\title{
DO VER AO SABER: ETNOGEOMORFOLOGIA POR MORADORES DE UMA comunidade rural no estado do Piauí
}

\author{
Karen Veloso Ribeiro*, Karoline Veloso Ribeiro², Emanuel Lindemberg Silva Albuquerque ${ }^{3}$, Roseli Farias \\ Melo de Barros ${ }^{4}$
}

1 Mestrado em Desenvolvimento e Meio Ambiente, Universidade Federal do Piaui, Av. Universitária, 1310, Bairro Ininga, CEP: 64049-550, Teresina-PI, Brasil. ORCID: 0000-0002-3944-6304

2 Mestranda em Geografia, Universidade Federal do Piaui, Av. Universitária, 1310, Bairro Ininga, CEP: 64049-550, Teresina-PI, Brasil. ORCID: 00000003-2697-6098

3 Docente da Universidade Federal do Piaui, Programa de Pós-Graduação em Geografia, Av. Universitária, 1310, Bairro Ininga, 64049-550, Teresina-PI, Brasil. ORCID: 0000-0003-3051-3301

4 Docente da Universidade Federal do Piauí, Programa de Pós-Graduação em Desenvolvimento e Meio Ambiente, Av. Universitária, 1310, Bairro Ininga, 64049-550, Teresina-PI, Brasil. ORCID: 0000-0001-9767-5546

* Autor para correspondência: karenveloso29@,hotmail.com

Recebido em 15 de maio de 2018. Aceito em 20 de março de 2019. Publicado em 31 de julho de 2019.

Resumo - A Etnogeomorfologia, como foco da abordagem etnoecológica, estuda o conhecimento que populações têm acerca dos processos geomorfológicos, considerando os saberes sobre a natureza e os valores da cultura e da tradição local. A importância atribuída a esta pesquisa encontra-se associada à identificação das formas de relevo predominantes na bacia hidrográfica do rio Mulato, sob a ótica dos moradores da comunidade Furnas, situada no município de Jardim do Mulato, estado do Piauí. Os procedimentos metodológicos pautaram-se pelo viés da Etnogeomorfologia, sendo que as informações foram analisadas qualitativamente, com o auxílio das técnicas de geoprocessamento. Diante do trabalho realizado, foi possível identificar quatro tipos de morfoesculturas de acordo com os saberes etnogeomorfológicos, a saber: Chapadas, Costaneiras/ Morros, Baixão e Baixa. A partir da interpretação das morfoesculturas, em consonância com sua morfodinâmica, as formas de relevo foram classificadas em: Planaltos Tabulares / Morros Testemunhos, Planaltos Rebaixados, Planícies Fluviais e Vales Interfluviais. Conclui-se que o etnoconhecimento dos moradores pesquisados se aproxima do conhecimento científico, uma vez que, munido do produto temático e da aferição em campo, foi possível constatar tais informações.

Palavras-chave: Relevo; paisagem; conhecimento local.

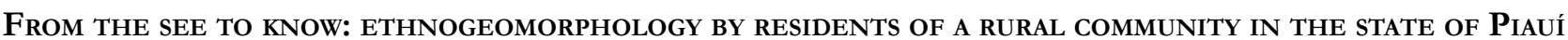

Aвstract - The ethnogeomorphology, as the focus of the ethnoecological approach, studies the knowledge that populations have about geomorphological processes, considering the knowledge about the nature and values of culture and local tradition. The importance attributed to this research is associated to the identification of the predominant relief forms in the Mulato river basin, from the perspective of the residents of the Furnas community, located in the municipality of Jardim do Mulato, in the state of Piauí. The methodological procedures were based on the ethnogeomorphology bias, and the information was analyzed qualitatively, with the aid of geoprocessing techniques. In view of the work carried out, it was possible to identify four types of morpho-sculptures according to the ethnogeomorphological knowledge, namely: Chapadas, Costaneiras/Hills, Baixão and Baixa. From the interpretation of the morpho-sculptures, in accordance with their morphodynamics, the relief forms were classified in: Tabular Plateaus/Inselbergs, Lowered Plateaus, Fluvial Plains and Interfluvial Valley. It is concluded that the ethno-knowledge of the residents studied is close to the scientific knowledge, since, provided with the thematic product and the field assessment, it was possible to verify such information. 
KEYwORDs: Relief; landscape; local knowledge.

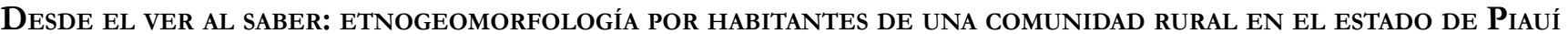

Resumen - La Etnogeomorfología, como centro del enfoque etnoecológico, estudia el conocimiento que las poblaciones tienen acerca de los procesos geomorfológicos, considerando los saberes sobre la naturaleza y los valores de la cultura y de la tradición local. La importancia atribuida a esta investigación se encuentra asociada a la identificación de las formas de relieve predominantes en la cuenca hidrográfica del río Mulato, bajo la óptica de los habitantes de la comunidad Furnas, situada en el municipio de Jardim do Mulato, estado de Piauí. Los procedimientos metodológicos se basaron en el sesgo de la Etnogeomorfología, siendo que las informaciones fueron analizadas cualitativamente, con el auxilio de las técnicas de geoprocesamiento. Ante el trabajo realizado, fue posible identificar cuatro tipos de morfoesculturas de acuerdo con los saberes etnogeomorfológicos, a saber: Mesetas, Costaneras / Cerros, Valle y Llanura. A partir de la interpretación de las morfoesculturas, en consonancia con su morfodinámica, las formas de relieve se clasificaron en: Mesetas Tabulares / Cerros Testigos, Altiplanicies rebajadas, Llanuras Aluviales y Valles Interfluviales. Se concluye que el etnoconocimiento de los habitantes encuestados se acerca al conocimiento científico, ya que, provisto del producto temático y de la medición en campo, fue posible comprobar dichas informaciones.

Palabras Clave: Relieve; paisaje; conocimiento local.

\section{INTRODUÇÃO}

A Geomorfologia é a ciência que estuda as formas de relevo, correspondendo esta à expressão espacial de uma superfície, compondo, assim, as diversas formas das paisagens morfológicas. Em síntese, corrobora-se que o aspecto visível de sua configuração escultural caracteriza o modelado topográfico de uma área, uma vez que as formas resultam da ação de determinado processo ou grupo de processos na superfície terrestre (Christofoletti 1980).

Como componente do estrato geográfico, no qual vive o homem, o relevo fornece não apenas conhecimento sobre os aspectos e a dinâmica da topografia atual, mas contribui de forma significativa para compreender a análise das formas e dos processos (Casseti 1991), sendo assim, passíveis de familiarização pelo conjunto de aparências que adquirem nas paisagens (Souza 2013).

Ribeiro (2012) menciona que ao considerar a importância que o relevo assume nos estudos geomorfológicos, a Etnogeomorfologia, como foco de abordagem etnoecológica, estuda o conhecimento acerca dos processos geomorfológicos, por meio da análise do conhecimento popular local, levando em consideração os saberes sobre a natureza e os valores da cultura e da tradição.

Vale salientar que esta abordagem parte do princípio de que o ambiente, constituído de seres, saberes, relações e culturas, busca na reconstrução histórica da relação sociedade/natureza, obter um diagnóstico vernacular para a compreensão de padrões de ocupação e organização do espaço geográfico (Diegues 1996).

Diante das particularidades e dos diversos padrões ocupacionais, a Etnogeomorfologia surge com o objetivo de incluir e compreender o papel do homem como um agente ativo dentro desse sistema geomorfológico, sob a ótica do entendimento e de práticas tradicionais que as comunidades exercem sobre a paisagem (Lopes e Ribeiro 2016), tendo em vista a intrínseca relação que permeia a sociedade e a natureza.

Perante a carência de pesquisas etnogeomorfológicas, particularmente, no Piaú, e ao considerar as variadas formas de relevo contidas no referido Estado, derivadas essencialmente das formações da Bacia Sedimentar do Parnaíba, passou-se a vislumbrar a bacia hidrográfica do rio Mulato, sob a ótica da comunidade Furnas, situada no município de Jardim do Mulato, como um espaço geográfico propício ao desenvolvimento dessa pesquisa. 
Destaca-se que a bacia hidrográfica ou bacia de drenagem, na acepção de Christofoletti (1980) é definida como a área drenada por um rio e seu sistema fluvial, classificada, segundo o critério funcional, como um sistema não isolado, aberto, de estrutura morfológica bem definida e passível de medições das variáveis que a compõe. Portanto, a escolha da comunidade Furnas é justificada pelo fato da mesma estar situada no alto curso da bacia hidrográfica em análise, o que tende a possibilitar outros estudos comparativos com comunidades localizadas no médio e baixo curso fluvial, tendo em vista que a bacia hidrográfica é um todo integrado.

Nesse viés, objetivou-se verificar as unidades de relevo existentes na área em epígrafe, no intuito de identificálas, diferenciá-las e classificá-las, considerando os saberes sobre a natureza e os valores da cultura e da tradição local, em consonância com o conhecimento científico. Ao conhecer seus processos e formas correlatas, a pesquisa almeja servir como subsídio para a elaboração de políticas públicas pautadas sob a ótica do etnoconhecimento local.

\section{Material e Métodos}

A bacia hidrográfica do rio Mulato (Figura 1) engloba, no todo ou em parte, oito municípios piauienses: Amarante, Angical do Piauí, Hugo Napoleão, Jardim do Mulato, Palmeirais, Regeneração, Santo Antônio dos Milagres e São Gonçalo do Piauí. Diante da abrangência e extensão da bacia hidrográfica mencionada, e seguindo o critério das maiores cotas altimétricas no referido setor espacial em análise, a qual é considerada de extrema importância para esse estudo, optou-se pela escolha do município de Jardim do Mulato, sob a ótica da comunidade Furnas, para o desenvolvimento dessa pesquisa, tendo em vista que esta encontra-se localizada no alto curso fluvial.

Figura 1. Mapa de localização da comunidade Furnas, município de Jardim do Mulato (Piauí, Brasil).

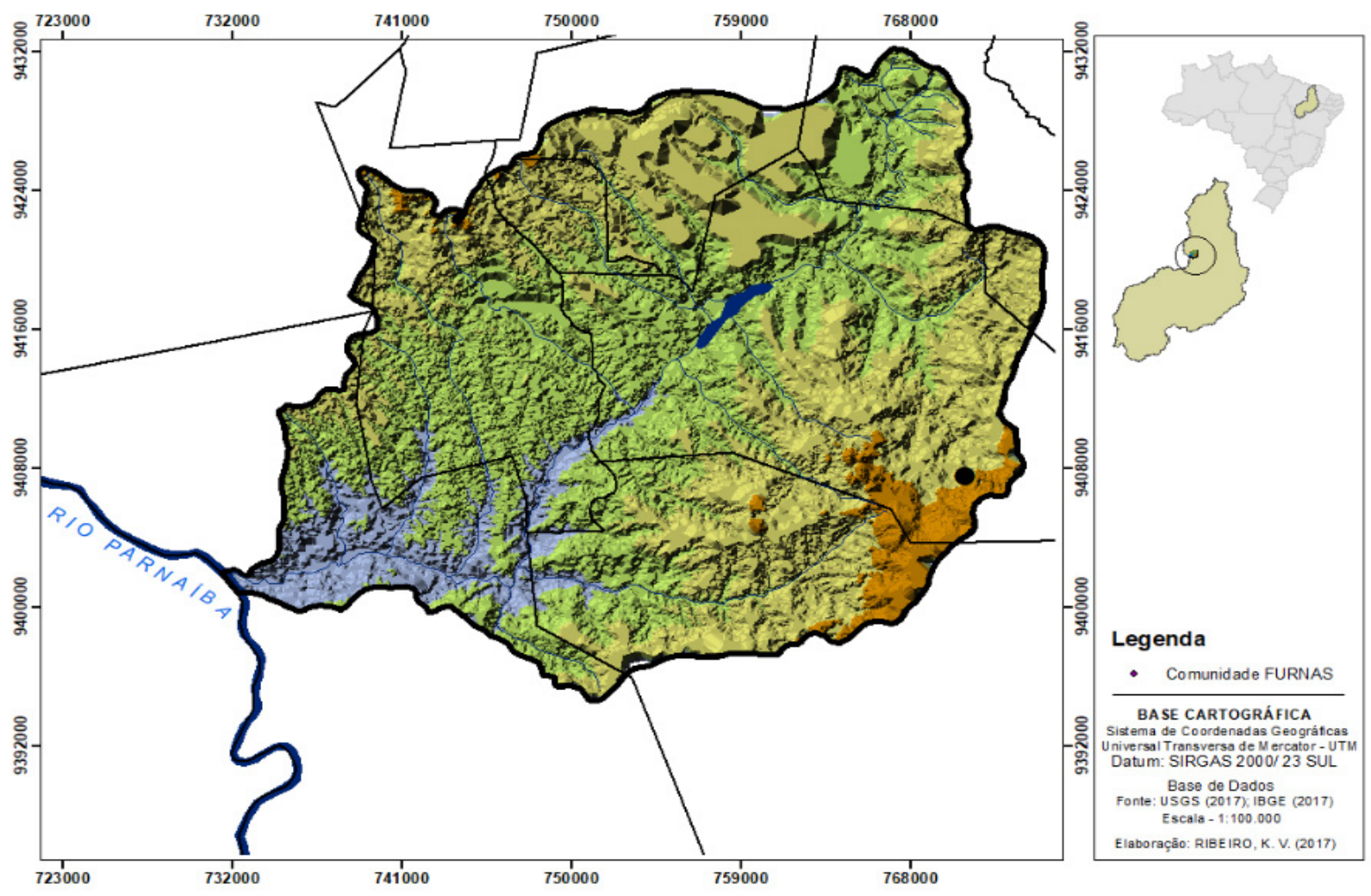

Fonte: IBGE (2010). Elaboração: RIBEIRO, em 2018. 
Salienta-se que a área de abrangência da bacia hidrográfica do rio Mulato encontra-se alicerçada sobre um ambiente de estrutura sedimentar, com predomínio de formações geológicas que datam do Paleomesozoico, tais como as formações: Corda, Pastos Bons, Pedra de Fogo, Piauí e a Formação Sardinha, conforme destaca Brasil (2017). De acordo com Lira Filho (2011), a atual estrutura e morfoescultura das unidades de relevo da bacia hidrográfica em destaque são resultantes da ação tecnosedimentar e climática pretérita, além dos agentes endógenos e exógenos que atuam na estrutura geológica.

Ao considerar a classificação geomorfológica de Lima (1987), a bacia hidrográfica do rio Mulato encontra-se inserida no compartimento regional do relevo que compreende os Baixos Planaltos do Médio-Baixo Parnaíba, com altitudes que variam de 90 a 160 metros nas proximidades da foz do rio Mulato no rio Parnaíba, e de 300 a 400 metros nos Planaltos Rebaixados e Morros Testemunhos do tipo mesa no alto curso fluvial. Vale ressaltar, também, que as cotas altimétricas aumentam no sentido oeste-leste, estando o município de Jardim do Mulato inserido nas cotas de maior expressividade.

Na perspectiva de alcançar os objetivos traçados na pesquisa em pauta, corrobora-se que: a coleta de dados se deu por entrevistas semiestruturadas (Bernard 2006) com agricultores que possuíam faixa etária igual ou superior a 18 anos, por meio de formulários, contendo questões abertas e fechadas sobre relevo e paisagem e observação participante (Bogdan e Taylor 1975), realizada pela convivência entre pesquisador e pesquisado, destacando-se que tal método consistiu em conhecer e compreender a dinâmica e a realidade da região e mapeamento comunitário (Bernard 1988), cujo produto obtido foi elaborado pelos participantes por intermédio de croquis, com o intuito de reunir dados acerca da percepção ambiental dos entrevistados e, assim, confrontar as nomenclaturas científicas e locais.

No intuito de contemplar o viés metodológico do universo amostral definido por Begossi et al. (2010), menciona-se que todas as famílias residentes na comunidade Furnas, localizada no município de Jardim do Mulato, estado do Piauí, foram entrevistadas. De acordo com os autores citados, em comunidades inferiores a 50 famílias, a amostra deve corresponder à sua totalidade (100\%), sendo que a comunidade em análise é composta por somente quatro famílias. A pesquisa foi realizada com um agricultor de cada família, sendo três do gênero masculino e um do gênero feminino $(\mathrm{n}=4)$. A idade dos informantes variou de 56 a 69 anos e o tempo de moradia na localidade de 15 a 69 anos.

As informações foram analisadas qualitativamente, por meio de análise de discurso (Laville e Dionne 1999), cuja abordagem se fundamenta nas relações sociais com o ambiente em questão. A partir da comparação dos dados entre o saber popular etnogeomorfológico com o saber científico, foi possível realizar a construção do perfil topográfico da área estudada e, assim, verificar as similaridades e diferenças referentes às terminologias.

Bases cartográficas foram produzidas em ambiente de Sistema de Informação Geográfica (SIG), utilizando o software de geoprocessamento ArcGis 10.5 (licença estudantil), bem como a utilização da plataforma Google Earth, possibilitando, assim, uma diagnose acerca da caracterização topográfica/espacial da área em estudo.

No intuito de espacializar e validar as informações colhidas em campo, considerando a escala adotada (comunidade Furnas, município de Jardim do Mulato, estado do Piauí), foi realizado um mapeamento hipsométrico da área, a partir de dados da missão SRTM (Shuttle Radar Topography Mission) e da plataforma Google Earth, no intuito de gerar um perfil topográfico da área. Essa etapa objetivou contemplar uma melhor visualização na classificação do relevo, em consonância com o mapeamento comunitário realizado.

Fotografias também foram utilizadas para consubstanciar e enriquecer a pesquisa, além da utilização de um receptor do Sistema de Posicionamento Global (GPS), que propiciou atribuir espacialidade (coordenadas georreferenciadas) aos dados coletados em campo, bem como possibilitando a validação dos mesmos.

Destaca-se que esta pesquisa teve aprovação do Comitê de Ética em Pesquisa (CEP) da Universidade Federal do Piauí (UFPI), sob n ${ }^{\circ}$ do parecer 2100118, obedecendo aos critérios éticos da Resolução No 466/12 do Conselho Nacional de Saúde (CNS), solicitando previamente a assinatura do partícipe voluntário, junto ao Termo de Consentimento Livre e Esclarecido (TCLE), após uma breve exposição do estudo realizado. A pesquisa também 
foi cadastrada no Sistema Nacional de Gestão do Patromônio Genético e do Conhecimento Tradicional Associado (SisGen) sob número de cadastro A7A4B8B.

\section{Resultados e Discussão}

A comunidade Furnas, situada na área rural do município de Jardim do Mulato, estado do Piauí, consta atualmente com quatro famílias residentes, conforme os dados informados pelo Agente Comunitário de Saúde da localidade (em 2017), dado este também confirmado in loco. De acordo com o mesmo, a comunidade era habitada por 39 famílias, mas com o passar dos últimos 13 anos (2005-2018), foram "cedendo" seu espaço e, consequentemente, migrando para outros municípios em detrimento do avanço do agronegócio (plantio de soja (Glycine max (L.) Merr.) e eucalipto (Eucalyptus spp) na região (Figura 2). Os moradores que ainda residem no local foram aqueles que resistiram em função do conceito de lugar, considerando a questão do pertencimento, e por terem nascido e se criado na localidade, uma vez que este espaço geográfico é dotado de significados.

Figura 2. Monocultura de soja (Glycine max (L.) Merr.) em primeiro plano e eucalipto (Eucalyptus spp) em segundo plano na comunidade Furnas, município de Jardim do Mulato, estado do Piauí.

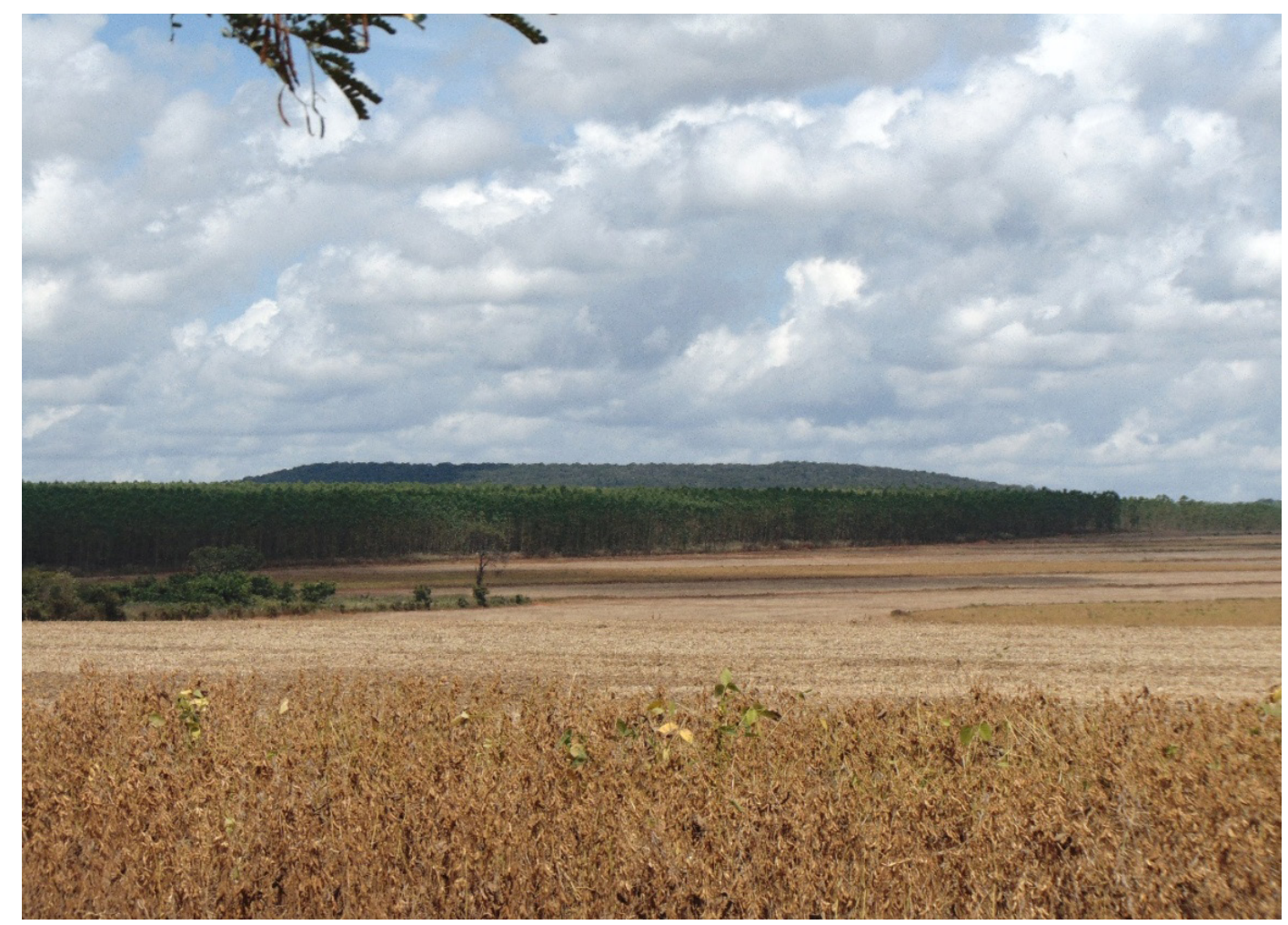

Fonte: RIBEIRO, em 2017.

Dos quatro entrevistados, três (75\%) possuem o Ensino Fundamental (incompleto) e apenas um (25\%) concluiu o Ensino Médio. Todos os moradores rurais integrantes da pesquisa nasceram e criaram no município de Jardim do Mulato, especificamente, na comunidade Furnas (Figura 3), onde tem nas suas práticas agrícolas seu maior conhecimento etnogeomorfológico referente à análise da paisagem. 
Figura 3. Visão panorâmica da comunidade rural Furnas, município de Jardim do Mulato/Piauí, com sede nas adjacências às áreas de produção agrícola.

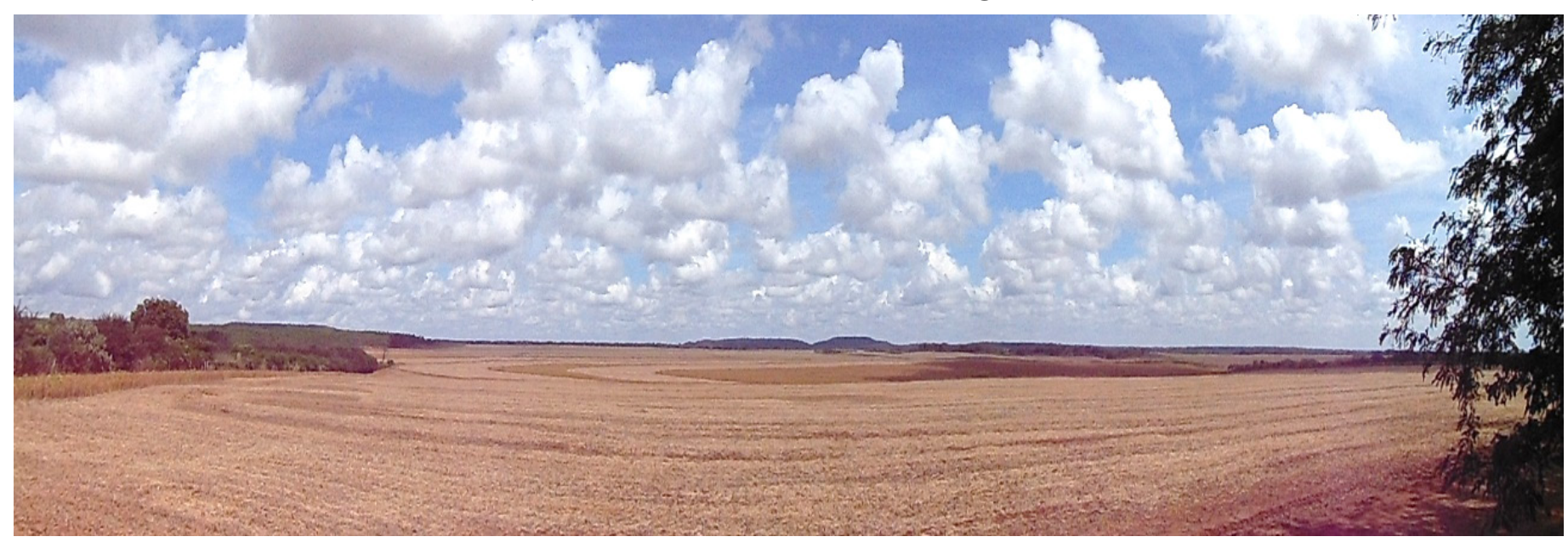

Fonte: RIBEIRO, em 2017.

Lopes e Pereira (2014) ressaltam que, tratando-se de conhecimento local, vários estudos etnocientíficos vêm demonstrando que as experiências repassadas por intermédio das gerações, assim como aquelas adquiridas pela vivência no lugar, possuem enorme expressividade na visão e na relação com o mundo que essas comunidades exercem. Daí a importância de se resgatar e, sobretudo, valorizar esses saberes indispensáveis a sua existência.

Nesse sentido, Ribeiro (2015) ao pesquisar os conhecimentos dos produtores rurais do Sítio Canabravinha, distrito de Palestina do Cariri, município de Mauriti/Ceará, identificou duas unidades de relevo: Serra (locais com declividades elevadas) e Área Plana (áreas com declividades muito baixas). De acordo com a autora, os produtores rurais entrevistados não conseguiram identificar grandes diferenças das morfoesculturas presentes neste setor espacial. Na pesquisa de Carvalho Neta et al. (2015), em Barbalha/Ceará, os produtores conseguiram fazer uma análise pormenorizada sobre as formas de relevo, fazendo distinção em quatro unidades gerais designadas: Chapada, Talhado (escarpa abrupta com quase $90^{\circ}$ de declividade), Pé de Serra (encosta da chapada) e Baixio.

Ao considerar o exposto, nota-se a importância do mapeamento etnogeomorfológico na identificação das formas de relevo, em associação com as características de uso, tendo em vista que as condições geológicas predominantes (condicionantes estruturais) têm um reflexo direto nas formas (condicionantes esculturais), o que tende a auxiliar em sua espacialização.

Em acréscimo ao mencionado, trazendo as análises e reflexões para a comunidade Furnas (recorte espacial do estudo), por meio da pesquisa direta, pode-se inferir que os informantes possuem notório conhecimento local acerca das diferentes formas de relevo predominantes nesse setor espacial. O contato diário e permanente dos agricultores com às áreas de cultivo e a observação cotidiana da paisagem permitiram fazer o reconhecimento e as classificações das mesmas, conforme foram retratadas no mapeamento comunitário (Figura 4). Em consonância com Alves e Ribeiro (2014), os produtores rurais conseguem identificar as diferentes morfoesculturas pela declividade do terreno. Além desta característica, é possível distinguir que o solo e a forma do relevo também são considerados distintivos na visão dos agricultores (Lopes e Pereira 2014). 
Figura 4. Mapeamento comunitário elaborado pelos atores sociais da pesquisa, com as nomenclaturas locais sobre as diferentes formas de relevo percebidas no terreno da comunidade Furnas, Jardim do Mulato/PI.

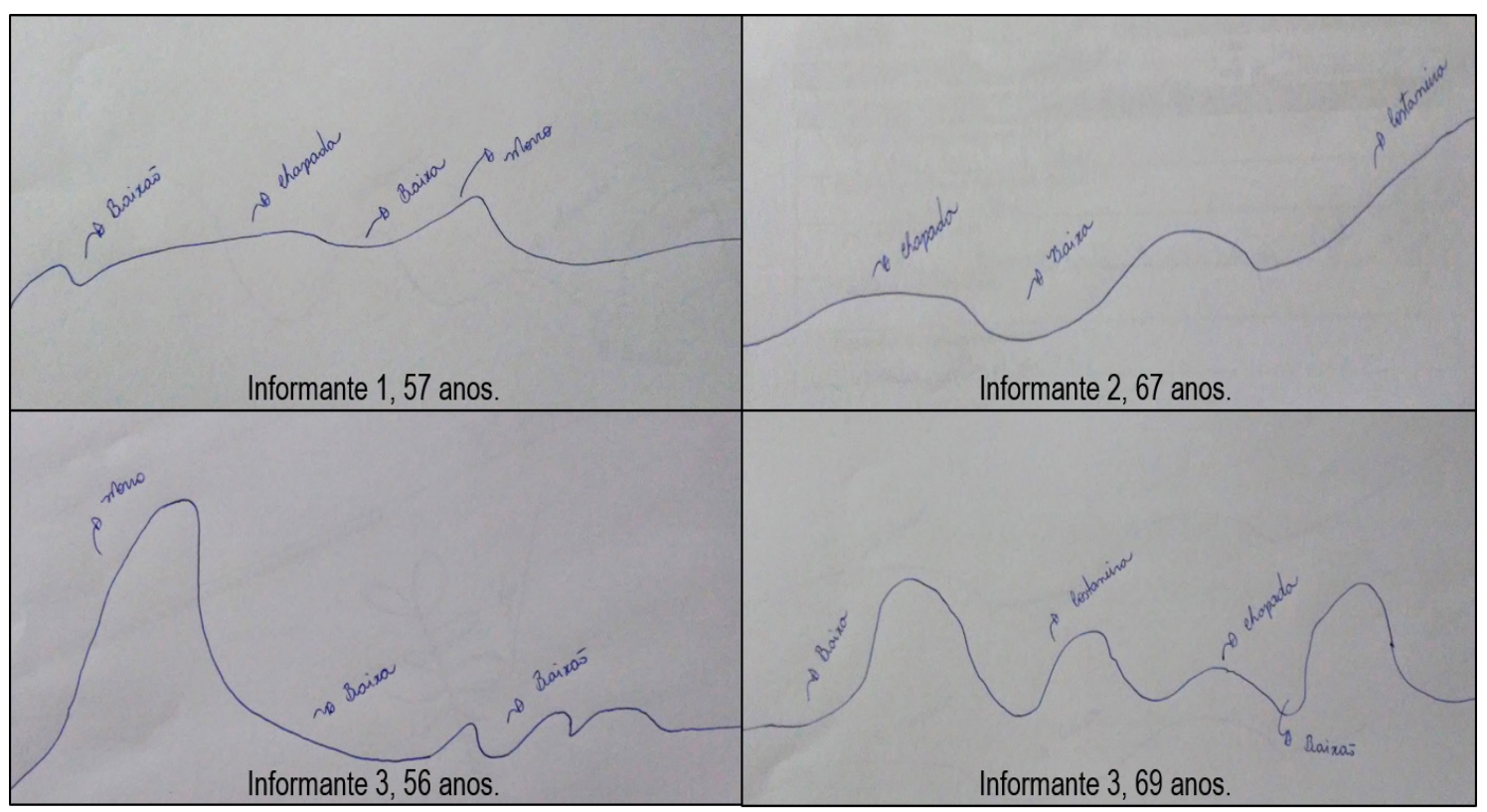

Fonte: RIBEIRO, em 2017.

De acordo com os saberes dos entrevistados, a partir da diferenciação das formas e análise topográfica do terreno (relevo), chegou-se às seguintes classificações etnogeomorfológicas (Figura 5): I) Costaneira ou morro (área inclinada), II) Chapada (área plana correspondente ao topo da costaneira), III) Baixa (área plana no "pé” da costaneira) e IV) Baixão (área rebaixada onde há acúmulo de água). Ao considerar a declividade da bacia hidrográfica do rio Mulato, a Costaneira ou morro constitui-se de relevos suaves planos a ondulados, correspondendo a terrenos movimentados com predomínio de formas acidentadas e altitude de aproximadamente 300 metros. A chapada se encontra na parte mais elevada com altitude superior a 300 metros, geralmente constituída de planaltos tabulares e morros testemunhos, constituindo-se de terreno forte ondulado. Na Baixa e Baixão predominam relevos planos a suaves planos com altitudes que variam de 150 a 290 metros, ocorrendo próximas aos cursos d'água. Observou-se terreno pouco movimentado, onde os desníveis de uma feição em relação a outra são quase inexistentes.

Figura 5. Perfil topográfico da comunidade Furnas, município de Jardim do Mulato/Piauí/ Brasil.

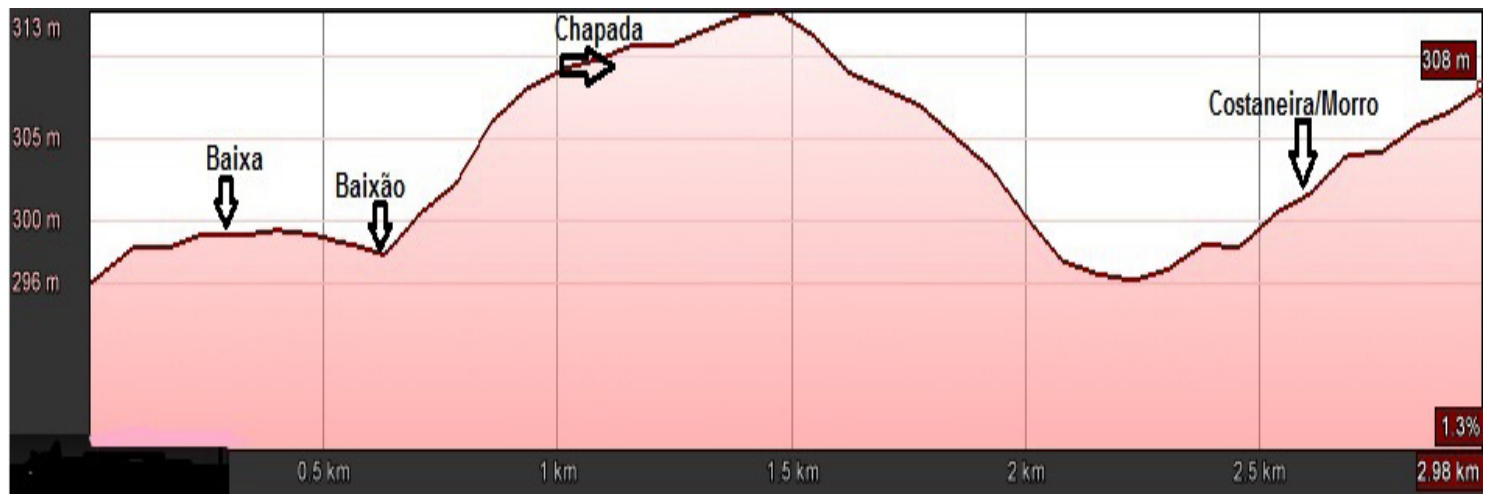

Fonte: Google Earth. Elaboração: ALBUQUERQUE, em 2018.

Em termos comparativos, as formas de relevo anteriormente mencionadas correspondem, sucessivamente aos: I) Planaltos Rebaixados/Planaltos Tabulares, II) Morros Testemunhos, III) Planícies Fluviais e IV) Vales Interfluviais. No que diz respeito à análise da paisagem, todos relataram perceber uma variação altimétrica em 
relação às formas de relevo que foram identificadas e mencionadas. A direção do fluxo das águas das chuvas consiste em outra variante observada pelos entrevistados, a qual permitiu a sua identificação.

Os informantes também evidenciaram que os animais e plantas que vivem sobre as morfoesculturas supracitadas diferem de uma para a outra, tendo o habitat desses seres como outro condicionante determinante para a identificação dessas fisionomias. Tal discurso foi percebido na fala que se segue:

"Bode não gosta de chapada, porque é reto. Eles gostam de tá subindo e descendo!

(Informante 1, 57 anos).

Esta passagem salienta que a ecologia do animal também diz muito sobre as diferentes formas de relevo em que se encontram inseridas. Ainda de acordo com os entrevistados, caprinos e ovinos são costumeiramente observados em áreas de costaneiras ou morros, diferentemente dos bovinos que optam por áreas mais baixas.

No que diz respeito aos cultivos, os atores sociais preferem plantar nas baixas ou baixões, por serem mais úmidas e frias, em relação à chapada e à costaneira, que são mais quentes e secas. Todavia ressaltam que as partes mais elevadas também se tornam propícias ao plantio, se bem irrigadas, aradas, adubadas e corrigidas com calcário, como descrito nas menções abaixo:

"Na chapada só dá legume se o inverno (verão chuvoso) for bom"

(Informante 3, 56 anos).

"Terra plana não dá nada, mas se adubada dá tudo" (Informante 4, 69 anos).

Nesta perspectiva, Ribeiro (2015) destaca em seus estudos que as áreas rebaixadas se tornam mais férteis em virtude do escoamento das águas das chuvas, que levam consigo solos das áreas mais declivosas, potencializando o acúmulo desses sedimentos nas áreas mais rebaixadas. Ainda acrescenta, que para a produção de cultivos não declinar nas áreas mais elevadas, os agricultores costumam melhorar o solo, seja fazendo rotação de cultura, adubando ou realizando irrigação por aspersão, atestando os resultados dessa pesquisa.

Por sua vez, Alves e Ribeiro (2014) salientam que as áreas comumente designadas de baixa ou baixada são destinadas majoritariamente a atividade da agricultura, em virtude de possuírem solos argilosos e férteis, diferentemente da chapada ou região plana, cuja prática agrícola é essencialmente desempenhada na quadra chuvosa (meses de janeiro a maio), dando lugar ao exercício do pastoreio no período de estiagem.

Apesar da altitude (altura para os atores sociais da pesquisa) constituir fator preponderante dentro dessa escala de análise, a temperatura ambiente e os cursos d'água foram outros fatores que levaram os agricultores a distinguirem as morfoesculturas presentes na comunidade Furnas, contribuindo, assim, para o discernimento dos produtores rurais frente às diferentes unidades de relevo existentes.

Nesse mesmo viés, os produtores rurais ressaltaram a importância da temperatura local, uma vez que, segundo os próprios moradores, futuramente, esta tende a ser alterada, em função do intenso desmatamento que vem ocorrendo nesta última década, em decorrência, sobretudo, do agronegócio, onde os entrevistados enfatizam ser a costaneira ou morro e a chapada como áreas quentes e o baixão e a baixa relativamente frios, como demonstrado no discurso subsequente:

"Com o tempo, daqui a pouco, não tem mais lugar frio por causa do desmatamento" (Informante 1, 57 anos).

Rodrigues (2012) acentua que as principais causas dos impactos ambientais do campo no cenário atual decorrem principalmente do desmatamento e da monocultura. Com isso, pode-se inferir que o fator temperatura 
e, consequentemente, a disponibilidade de água, logo deixarão de serem considerados aspectos relevantes para as características de diferenciação entre as formas de relevo (etnogeomorfologia para as futuras gerações), tendo em vista uma tendência de uniformização na área em epígrafe, ocasionado, principalmente, pelo avanço do agronegócio da soja na região.

\section{ConClusão}

A comunidade Furnas, localizada na zona rural do município de Jardim do Mulato, estado do Piauí, vem passando, nos últimos anos, por intensas alterações no quadro ocupacional, tendo em vista o intenso avanço do agronegócio da soja e eucalipto na região. Como fruto desse processo, muitos moradores tiveram que migrar para dar lugar as grandes fazendas com monocultivos.

A partir da elaboração do perfil topográfico, assim como da relação que os produtores rurais possuem da análise da paisagem, foi possível traçar de forma nítida a classificação etnogeomorfológica da área em epígrafe, de acordo com os saberes dos entrevistados e articular esses conhecimentos ao viés científico, uma vez que os moradores foram nascidos e criados na comunidade, possibilitando, assim, identificar e classificar as formas de relevo por meio da realidade visual que os mesmos possuem do espaço geográfico.

Tendo em vista as classificações etnogeomorfológicas identificadas, constatou-se que os residentes possuem notório saber sobre as formas de relevo presentes na área estudada, o que torna relevante considerar o conhecimento empírico dos atores sociais, por compreenderem com mais aptidão a dinâmica social da localidade, decorrente da vivência, do íntimo contato da população com o ambiente e, sobretudo, diante do compartilhamento de informações entre as gerações e entre os membros da comunidade, contribuindo, sobremaneira, na conservação e perpetuação dos saberes populares.

Assim como as demais Etnociências, os estudos etnogeomorfológicos podem auxiliar na compreensão e interpretação do espaço geográfico, por levar em consideração os saberes empíricos que populações tradicionais/ locais detêm do meio em que vivem. Portanto, se inexistirem informações acerca das feições morfoesculturais de determinado local e/ou do ambiente, de maneira geral, os saberes tradicionais/locais se tornam imprescindíveis na construção e/ou no resgate destas, por carregarem consigo referências valiosas que partem não somente da observação do dia a dia da paisagem, mas também das experimentações advindas das práticas exercidas no espaço de trabalho cotidiano, o que permite a elaboração de diagnoses e análises úteis no desenvolvimento de pesquisas junto às comunidades.

\section{REFERÊNCIAS}

Alves JTO, Ribeiro SC. 2014. Etnogeomorfologia: classificação das formas de relevo segundo a percepção dos agricultores do Sítio Cidade no município de Caririaçu/CE. Revista Geonorte, Edição Especial 4, (10)1:77-80.

Begossi A, Lopes PF, Oliveira LEC, Nakano H. 2010. Ecologia de Pescadores Artesanais da Baía de Ilha Grande. Rima Editora: São Carlos, 298p.

Bernard HR. 1998. Research methods in cultural anthropology. Sage Publications: Newbury Park, 520p.

Bernard HR. 2006. Research methods in cultural anthropology. $2^{\mathrm{a}}$ ed. SAGE Publication: Newbury Park, 803p.

Bogdan R, Taylor SJ. 1975. Introduction to qualitative research methods: a phenomenological approach to the social sciences. J. Wtley: New York, 266p. 
BRASIL. CPRM - Serviço Geológico do Brasil. Projeto Geobank. 2017. Disponível em: http://geosgb.cprm.gov.br/. Acessado em: 24 de novembro de 2017.

Carvalho-Neta ML, Ribeiro SC, Marçal MS, Lima GG. 2014. Mapeamento etnogeomorfológico do distrito de Arajara, Barbalha/CE. Revista Geonordeste, Edição especial 4, (10)1:208-212.

Casseti W. 1991. Ambiente e apropriação do relevo. Contexto: São Paulo, 147p.

Christofoletti A. 1980. Geomorfologia. Editora Blucher: São Paulo, 188p.

Diegues ACS. 1996. O mito moderno da natureza intocada. Hucitec: São Paulo, 169p.

Laville C, Dionne J. 1999. A construção do saber: manual de metodologia da pesquisa em ciências humanas. Artmed: porto alegre; Editora UFMG: Belo Horizonte, 340p.

Lima IMMF. 1987. Relevo piauiense: uma proposta de classificação. Carta Cepro. Teresina, (2)2:55-84.

Lira-Filho MAS. 2011. Análise geoecológica da bacia hidrográfica do Rio Mulato. Universidade Federal do Piauí, Departamento de Geografia, 83p.

Lopes VM, Ribeiro SC. 2016. Etnogeomorfologia e Paisagem. Revista de Geociências do Nordeste, 2 (especial), 212-220.

Lopes VM, Pereira CEG. 2014. O homem, o relevo e a cultura: Etnogeomorfologia sertaneja na região Sul do Ceará - Brasil. Anais do VI Congresso Iberoamericano de Estudios Territoriales y Ambientales, São Paulo, 3164-3181.

Ribeiro SC. 2012. Etnogeomorfologia sertaneja: proposta metodológica para a classificação das paisagens da subbacia do rio Salgado/CE. Universidade Federal do Rio de Janeiro, Departamento de Geografia, 282p.

Ribeiro SC. 2015. Etnogeomorfologia sertaneja - estudo dos conhecimentos dos produtores rurais do Sítio Canabravinha, distrito de Palestina do Cariri - Mauriti/CE acerca dos processos morfodinâmicos. Revista Geosaberes, 6(2): 103-112.

Rodrigues GS. 2012. Impactos ambientais da agricultura. In: Hammes VS. (Ed. Técnico). Educação ambiental para o desenvolvimento sustentável: Julgar: percepção do impacto ambiental, Brasília/DF: Embrapa, p. 143-147.

Souza JCO. 2013. Identificação de geossistemas e sua aplicação no estudo ambiental da bacia hidrográfica do rio São Miguel - Alagoas. Universidade Federal de Pernambuco, Departamento de Ciências Geográficas, 213p.

Tuan Yi-Fu. 1983. Espaço e lugar: a perspectiva da experiência. Difel: São Paulo, 250p. 